\title{
PARAMETRIC X-ray RADIATION IN POLYCRYSTALS
}

\author{
V.I. Alekseev ${ }^{1}$, A.N. Eliseyev ${ }^{1}$, E.F. Irribarra ${ }^{3}$, I.A. Kishin ${ }^{1,2}$, A.S. Kubankin ${ }^{1,2}$, \\ R.M. Nazhmudinov ${ }^{1,2}$ \\ ${ }^{1}$ P. N. Lebedev Physical Institute RAS, 308007, Moscow, Russia; \\ ${ }^{2}$ Belgorod National Research University, 119991, Belgorod, Russia; \\ ${ }^{3}$ Escuela Politécnica Nacional, Departamento de Física, Quito, Ecuador
}

Parametric X-ray radiation produced during the interaction of charged particles with polycrystals is regarded. A review of the existing theories, perspectives of application and performed experiments is presented. The evolution of experimental capabilities as well as the progress in the process comprehension is illustrated. The state of the art of PXR in polycrystals is presented.

PACS: 537.8, 538.9, 535-1/-3, 535.4, 537.5

A large number of experimental and theoretical works were devoted to the research of radiation processes that take place when a charged particle moves in condensed matter. The radiation is generated in a wide spectral region during the charged particle interaction with atoms and the total generated radiation consists of the contributions from different radiation mechanisms, which can occur simultaneously. In some mechanisms the radiation is emitted by the charged particle because it moves with acceleration (Bremsstrahlung, Channelling Radiation), and in others the radiation is emitted by the polarized medium even if the particle velocity is constant (Transition Radiation, Cherenkov Radiation, Parametric X-ray Radiation, Polarization Bremsstrahlung) $[1-5]$.

The mechanism describing the radiation generated during the interaction of charged particles with polycrystals was theoretically described in [6]. The Parametric X-ray radiation spectrum in polycrystals consists of a set of peaks which position is determined by the observation angle. Additionally, it was established that the intensity and the spectral width are also determined by the observation angle achieving interesting properties in the backward geometry [7].

Several attempts were performed to verify the theoretical predictions. Some properties were validated separately, however a complete study was not achieved until this year [8]. The main problem to verify experimentally the theory was the presence of texture in the targets. Metallic polycrystalline foils have a predominant orientation of the grains according the crystallographic structure and the manufacturing process [9].

For the theory validation it was a problem but on the other hand, since PXR in polycrystals is sensitive to texture, grain size, lattice constant, etc., it can be used to measure these parameters. Possible applications of PXR in polycrystals have been described for structure diagnostics due to the spectrum dependence on the medium properties [10 - 14].

Parametric X-ray radiation in polycrystals (textured polycrystals and powders) has been studied experimentally since 1999 [15]. Several experiments were performed subsequently, mainly in three experimental facilities located in Russia and Japan. In Table are described the main characteristics of the experiments. The evolution of the experimental setup and the progress in the comprehension of PXR from polycrystals can be observed. It is interesting to observe that unlike PXR in crystals [3], PXR in polycrystals was generated only by electrons.

The general scheme of the experiments is presented in Fig. 1. Charged particles interact with polycrystalline targets, then the radiation is registered at the observation angle $\theta$ for a specific value of the orientation angle $\varphi$. The main characteristics of PXR in polycrystals were studied manipulating the orientation angle and the observation angle.

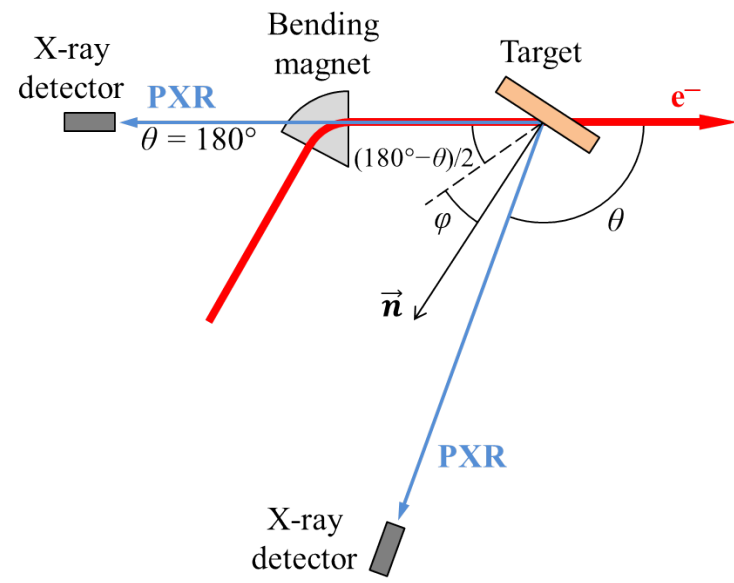

Fig. 1. Experimental scheme: $\theta$-observation angle;

$$
\varphi \text { - orientation angle; }
$$

$\vec{n}$ - normal to the target surface plane

In Fig. 2 is presented a spectrum of PXR in polycrystals. It was obtained after the interaction of a $7 \mathrm{MeV}$ electron beam with a tungsten polycrystalline foil when $\theta=180^{\circ}$. It can be observed that the intensity of the PXR peaks changes when $\varphi$ changes. Such behaviour confirms that the target presents texture. Additionally, theory affirms that in the analysed energy region, free from background peaks (CXR or escape peaks), five PXR peaks should manifest corresponding to crystallographic planes (110), (200), (211), (220), and (310). However, in Fig. 2 only peaks from planes (200) and (310) were reliably measured. This is the result of the texture influence and it represented the main problem to verify the theory. Unfortunately, it occurs with all kind of metallic foils. 
PXR experiments in polycrystals

\begin{tabular}{|c|c|c|c|c|c|}
\hline Year & $\begin{array}{c}\text { Country, } \\
\text { Energy }\end{array}$ & Target, planes & $\theta$ & Main findings & $\begin{array}{c}\text { Detector, } \\
\text { Energy resolution }\end{array}$ \\
\hline $\begin{array}{c}2019 \\
{[8]}\end{array}$ & \multirow{9}{*}{$\begin{array}{c}\text { Russia, Lebedev } \\
\text { Physical insti- } \\
\text { tute, department } \\
\text { of high energy } \\
\text { physics, } \\
7 \mathrm{MeV}\end{array}$} & $\begin{array}{l}\text { W powder, } \\
(110),(200),(211) \\
(220),(310)\end{array}$ & $\begin{array}{l}150.0^{\circ} \\
180.0^{\circ}\end{array}$ & $\begin{array}{l}\text { Absolute comparison of experi- } \\
\text { ment with theory [6]. Agreement } \\
\text { in position, form and amplitude for } \\
\text { all peaks simultaneously }\end{array}$ & $\begin{array}{l}\text { Silicon drift detector } \\
145 \mathrm{eV} \text { at } 5.9 \mathrm{keV}\end{array}$ \\
\hline $\begin{array}{l}2018 \\
{[16]}\end{array}$ & & $\begin{array}{l}\text { W textured foil } \\
\quad(200)\end{array}$ & $\begin{array}{l}90.8^{\circ} \\
119.6^{\circ} \\
151.0^{\circ} \\
180.0^{\circ}\end{array}$ & $\begin{array}{l}\text { Dynamic verification that the PXR } \\
\text { peaks intensity increases and the } \\
\text { spectral width decreases when } \theta \\
\text { approaches } 180.0^{\circ} \text {. } \\
\text { Textured polycrystals can be de- } \\
\text { scribed by the theory of PXR for } \\
\text { mosaic crystals }\end{array}$ & $\begin{array}{l}\text { Silicon drift detector } \\
145 \mathrm{eV} \text { at } 5.9 \mathrm{keV}\end{array}$ \\
\hline $\begin{array}{l}2018 \\
{[17]}\end{array}$ & & $\begin{array}{l}\text { Textured foils of } \\
\qquad \mathrm{Ni} \\
(220) \\
\mathrm{W} \\
(200),(310)\end{array}$ & $180.0^{\circ}$ & $\begin{array}{c}\text { Disadvantages of PXR compared } \\
\text { to XRD to measure the rocking } \\
\text { curves }\end{array}$ & $\begin{array}{l}\text { Silicon drift detector } \\
145 \mathrm{eV} \text { at } 5.9 \mathrm{keV}\end{array}$ \\
\hline $\begin{array}{l}2016 \\
{[18]}\end{array}$ & & $\begin{array}{l}\text { W textured foil } \\
\qquad(200)\end{array}$ & $180.0^{\circ}$ & $\begin{array}{l}\text { Discrimination of the contribution } \\
\text { from diffraction mechanisms of } \\
\text { real and virtual photons to the total } \\
\text { radiation yield. } \\
\text { Energy dependence of the PXR } \\
\text { peak on } \varphi \text { was observed }\end{array}$ & $\begin{array}{l}\text { Silicon drift detector } \\
137 \mathrm{eV} \text { at } 3.9 \mathrm{keV}\end{array}$ \\
\hline $\begin{array}{l}2015 \\
{[19]}\end{array}$ & & $\begin{array}{c}\mathrm{Al} \\
(111),(200),(220) \\
\mathrm{Ni} \\
(111),(200),(220) \\
\mathrm{Cu} \\
(111),(200),(220) \\
(311) \\
\mathrm{W} \\
(200) \\
\end{array}$ & $\begin{array}{r}75.0^{\circ} \\
90.0^{\circ} \\
83.0^{\circ} \\
180.0^{\circ}\end{array}$ & $\begin{array}{l}\text { Shift of the PXR peak position } \\
\text { when } \theta \text { changes. } \\
\text { Agreement with theory for indi- } \\
\text { vidual peaks. } \\
\text { Observation of several PXR peaks } \\
\text { not simultaneously. } \\
\text { PXR is generated in grains which } \\
\text { mean size is } 300 \mathrm{~nm}\end{array}$ & $\begin{array}{c}\text { Uncooled } \mathrm{Si}(\mathrm{Li}) \\
200 \mathrm{eV} \text { at } 5.9 \mathrm{keV} \\
\text { and } \\
\text { Silicon drift detector } \\
160 \mathrm{eV} \text { at } 4.9 \mathrm{keV}\end{array}$ \\
\hline $\begin{array}{l}2014 \\
{[20]}\end{array}$ & & $\begin{array}{c}\mathrm{Ni} \\
(111),(200),(220)\end{array}$ & $180.0^{\circ}$ & $\begin{array}{l}\text { PXR peaks are produced in grains } \\
\text { which average size is } 50 \mathrm{~nm} \text {. } \\
\text { PXR spectrum changes when } \varphi \\
\text { changes because of texture }\end{array}$ & $\begin{array}{c}\text { Silicon drift detector } \\
130 \mathrm{eV}\end{array}$ \\
\hline $\begin{array}{l}2013 \\
{[21]}\end{array}$ & & $\begin{array}{c}\mathrm{Ni} \\
(111),(200),(220)\end{array}$ & $180.0^{\circ}$ & $\begin{array}{l}\text { PXR peaks are produced in grains } \\
\text { which average size is } 300 \mathrm{~nm}\end{array}$ & $\begin{array}{c}\text { Silicon drift detector } \\
130 \mathrm{eV}\end{array}$ \\
\hline $\begin{array}{l}2012 \\
{[22]}\end{array}$ & & $\begin{array}{c}\mathrm{Cu} \\
(111),(220),(311) \\
\end{array}$ & $180.0^{\circ}$ & $\begin{array}{l}\text { PXR peaks are measured in the } \\
\text { backward geometry. }\end{array}$ & $\begin{array}{c}\text { PIN Si } \\
159 \mathrm{eV} \text { at } 5.9 \mathrm{keV} \\
\end{array}$ \\
\hline $\begin{array}{l}2008 \\
{[23]}\end{array}$ & & $\begin{array}{c}\mathrm{Al} \\
(111)\end{array}$ & $\begin{array}{l}75.0^{\circ} \\
90.0^{\circ}\end{array}$ & $\begin{array}{c}\text { Shift of the PXR peak position } \\
\text { when } \theta \text { changes }\end{array}$ & $\begin{array}{c}\text { Uncooled } \mathrm{Si}(\mathrm{Li}) \mathrm{PIN} \\
200 \mathrm{eV} \text { at } 5.9 \mathrm{keV}\end{array}$ \\
\hline $\begin{array}{c}2006 \\
{[24,25]}\end{array}$ & \multirow{2}{*}{$\begin{array}{c}\text { Japan, REFER } \\
\text { electron ring at } \\
\text { Hiroshima } \\
\text { University, } \\
150 \mathrm{MeV}\end{array}$} & \multirow[t]{2}{*}{$\begin{array}{c}\text { Mo, textured } \\
\text { polycrystalline } \\
\text { foil } \\
(110,(220),(112)\end{array}$} & $\begin{array}{l}11.2^{\circ} \\
25.8^{\circ}\end{array}$ & $\begin{array}{l}\text { PXR peaks from textured poly- } \\
\text { crystalline foil registered. } \\
\text { Orientation dependence measured } \\
\text { using XRD and PXR. } \\
\text { Energy independence of the PXR } \\
\text { peak on } \varphi \text { was reported }\end{array}$ & $\begin{array}{c}\text { Cooled } \mathrm{Si}(\mathrm{Li}) \\
380 \mathrm{eV} \text { at } 17.5 \mathrm{keV}\end{array}$ \\
\hline $\begin{array}{l}2001 \\
{[26]}\end{array}$ & & & $25.8^{\circ}$ & $\begin{array}{c}\text { "unidentified peaks" were observed } \\
\text { during the experiment from } \\
\text { an "amorphous" molybdenum foil }\end{array}$ & $\begin{array}{c}\text { Cooled } \mathrm{Si}(\mathrm{Li}) \\
450 \mathrm{eV} \text { at } 7.23 \mathrm{keV}\end{array}$ \\
\hline $\begin{array}{l}2004 \\
{[27]}\end{array}$ & \begin{tabular}{|c|} 
Hiroshima \\
University, X-ray \\
diffractometer \\
RIGAKU \\
RINT2000, \\
$8 \mathrm{keV}$ \\
\end{tabular} & $\begin{array}{l}\text { Mo, textured poly- } \\
\text { crystalline foil } \\
(110),(220),(112) \\
(200)\end{array}$ & $50^{\circ} \ldots 170^{\circ}$ & $\begin{array}{l}\text { The origin of the unidentified } \\
\text { X-ray spectral peaks observed } \\
\text { at the REFER was established } \\
\text { as manifestation of the PXR } \\
\text { from textured polycrystal }\end{array}$ & $\begin{array}{l}\text { X-ray film, scintilla- } \\
\text { tion X-ray detector }\end{array}$ \\
\hline $\begin{array}{l}1999 \\
{[15]}\end{array}$ & $\begin{array}{c}\text { Russia, Moscow } \\
\text { State University } \\
\text { Linac, } 2.4 \mathrm{Mev}\end{array}$ & $\begin{array}{c}\text { Al foil, } \\
\text { (111) and (220) }\end{array}$ & $90.0^{\circ}$ & PXR peaks observed. & \begin{tabular}{|c|} 
Cooled $\mathrm{Si}(\mathrm{Li})$ \\
Energy resolution not \\
reported, estimation \\
$500 \mathrm{eV}$ at $6 \mathrm{keV}$
\end{tabular} \\
\hline
\end{tabular}




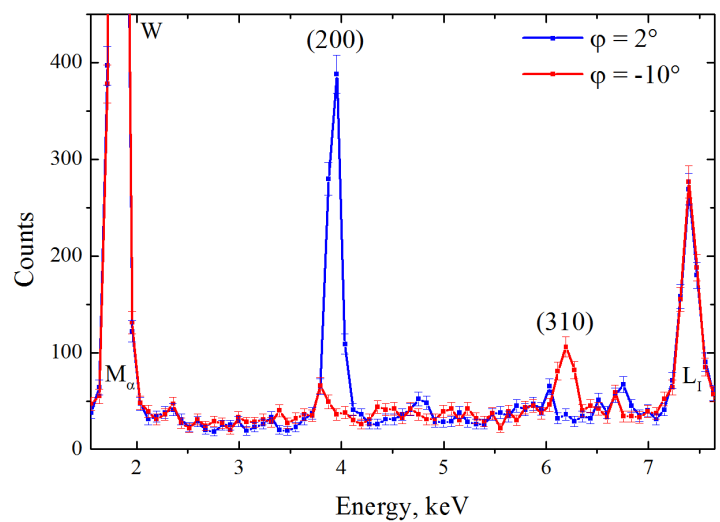

Fig. 2. PXR from a tungsten textured polycrystalline foil measured for two orientation angles $\varphi=2^{\circ}$ and $\varphi=-10^{\circ}$

To solve this inconvenient, experiments with powders were performed [8]. Unlike metallic foils, powders are constituted of randomly oriented grains. In this case, the manifestation of all PXR peaks was reliably fixed as shown in Fig. 3. The measurements were performed for two observation angles to highlight that the PXR peaks positions depends on $\theta$.

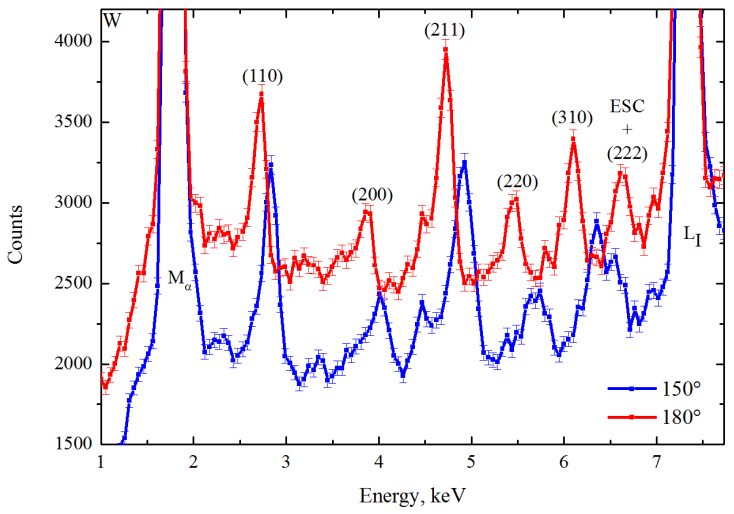

Fig. 3 PXR from tungsten powder measured for observation angles of $\theta=150^{\circ}$ and $\theta=180^{\circ}$

The main differences of PXR from crystals and polycrystals can be observed in the spectra, the orientation dependences and the intensity.

For example, the PXR spectrum from crystals presents only one peak and its harmonics while the spectrum from polycrystals presents a set of peaks from different crystallographic planes. The case of texture polycrystals can be regarded as a transition, then the spectrum can present one or more peaks depending on the texture degree. The dependence of PXR yield on the orientation angle differs substantially also. The rocking curve for crystals presents two peaks symmetrically distributed around the specular condition at $\varphi=\gamma^{-1}$, for textured polycrystal metallic foils it was observed only one peak at the specular condition and finally it is a constant for polycrystals. The PXR energy peak dependence on the orientation angle can be listed as the last example of the differences. It changes for crystals and textured polycrystals but remain a constant for polycrystals.

It is important to mention that despite the perspectives to apply PXR in polycrystals some disadvantages have been already reported. For example, it was proposed [25] that polycrystals can be used instead of crysISSN 1562-6016. BAHT. 2019. №4(122) tals to generate quasimonochromatic X-ray beams because of a higher resistance to mechanical damage produced by the charged particle beam. However, it was shown that the destruction of Si crystals is related to the heating during one micropulse, if the micro pulse duration is smaller than $5 \mu \mathrm{s}$, currents of $300 \mathrm{~mA}$ can be achieved [28]. Similarly, it was shown that the rocking curves obtained by PXR are wider than those obtained by commonly used diffraction methods because of the influence of the initial angular divergence of the charged particle Coulomb field [17].

Even though some limitations have been reported additional studies should be performed to explore the possibilities for applications and to clarify fundamental questions such as the radiation formation length, the differences in the diffraction mechanisms of virtual and real photons and others.

\section{ACKNOWLEDGEMENTS}

The work was supported the scholarship of the President of the Russian Federation for young scientists and graduate students number SP-765.2019.2, by the grant of the President of Russia for young doctors of sciences MD-5748.2018.2 and by the project No. PIJ-16-03 of the Escuela Politécnica Nacional.

\section{REFERENCES}

1. Y.B. Fainberg, N.A. Khyzhniak. On parametric Xrays of fast charged particles in periodic media // Journal of Experimental and Theoretical Physics. 1957, v. 32, p. 883 (in Russian).

2. M.L. Ter-Mikaelian. High Energy Electromagnetic Processes in Condensed Media. 1972.

3. V.G. Baryshevsky, I. Feranchuk, A. Ulyanenkov. Parametric X-Ray Radiation in Crystals. SpringerVerlag Berlin Heidelberg, 2005.

4. A.P. Potylitsyn. Electromagnetic Radiation of Electrons in Periodic Structures. Springer Berlin Heidelberg, 2011.

5. A.V. Shchagin. Fresnel coefficients for parametric X-ray (Cherenkov) radiation // Physics - Uspekhi. 2015, v. 58, p. 819-827.

6. N.N. Nasonov. Collective effects in the polarization bremsstrahlung of relativistic electrons in condensed media. // NIM. Section B. 1998, v. 145, p. 19-24.

7. V. Astapenko, N. Nasonov, P. Zhukova. Anomalous peak in the spectrum of polarizational bremsstrahlung from relativistic electrons moving through a solid target // Journal of Physics B. 2007, v. 40, p. 1337-1346.

8. V.I. Alekseev, A.N. Eliseyev, E. Irribarra, et al. Parametric X-ray radiation from powders // Physics Letters A. 2019, v. 383, p. 770-773.

9. H. Wenk, P.V. Houtte. Texture and anisotropy // Reports on Progress in Physics. 2004, v. 67, p. 1367.

10. V.A. Shchagin. Possibilities for measurement of nano-crystallites size with use of parametric X-ray radiation // Journal of Physics: Conference Series. 2010, v. 236, p. 012020.

11. I. Lobach, A. Benediktovitch. Theoretical Analysis of Orientation Distribution Function Reconstruction of Textured Polycrystal by Parametric X-rays // 
Journal of Physics: Conference Series. 2016, v. 732, p. 012015 .

12. I. Lobach, A. Benediktovitch, I. Feranchuk, A. Lobko. Parametric X-rays from a polycrystalline target // NIM. Section B. 2015, v. 360, p. 75-80.

13. N. Nasonov, P. Zhukova, V. Sergienko. Polarization bremsstrahlung in a backward direction for medium structure diagnostics // Journal of Physics: Conference Series. 2010, v. 012017, p. 236.

14. A.S. Kubankin, N.N. Nasonov. On the possibility of using parametric X-ray radiation to study anisotropy of a crystal mosaic structure, Journal of Surface Investigation.X-ray // Synchrotron and Neutron Techniques. 2008, v. 2, p. 317-320.

15. S. Blazhevich, A. Chepurnov, V. Grishin, et al. Polarization bremsstrahlung of relativistic electrons in aluminium // Physics Letters A. 1999, v. 254, p. $230-232$.

16. V.I. Alekseev, A.N. Eliseyev, E. Irribarra, et al. Evolution of the characteristics of Parametric X-ray Radiation from textured polycrystals under different observation angles // Physics Letters A. 2018, v. 382, p. 503-506.

17. V.I. Alexeyev, A.N. Eliseyev, E. Irribarra, et al. Parametric Xray Radiation And Texture Of Polycrystalline Foils // Resource-Efficient Technologies. 2018, v. 2, p. 12-15.

18. V.I. Alexeyev, A.N. Eliseyev, E. Irribarra, et al. Observation of parametric X-ray radiation in an anomalous diffraction region // Physics Letters A. 2016, v. 380, p. 2892-2896.

19. V.I. Alekseev, A.N. Eliseev, E.F. Irribarra, et al. Research of the polarization bremsstrahlung of relativistic electrons in polycrystalline targets // NIM. Section B. 2015, v. 342, p. 47-51.

20. V.I. Alekseev, A.N. Eliseev, E.F. Irribarra, et al. Diagnostics of nanodisperse polycrystals based on the polarization bremsstrahlung of relativistic electrons // Journal of Surface Investigation. X-ray, Syn- chrotron and Neutron Techniques. 2014, v. 8, p. 347-350.

21. V.I. Alekseev, E.F. Irribarra, A.S. Kubankin, et al. Experimental study of polarization bremsstrahlung from small-grained polycrystals // Journal of Surface Investigation. X-ray, Synchrotron and Neutron Techniques. 2013, v. 7, p. 276-278.

22. V.I. Alekseev, K.A. Vokhmyanina, A.N. Eliseev, et al. Measuring coherent peaks of polarization bremsstrahlung from relativistic electrons in polycrystalline targets in backscattering geometry // Technical Physics Letters. 2012, v. 38, p. 294-296.

23. N.A. Gostishchev, A.S. Kubankin, N.N. Nasonov, et al. Angular dependence of the coherent peak position in the polarization bremsstrahlung spectrum of relativistic electrons in polycrystalline targets // Technical Physics Letters. 2008, v. 34, p. 763-764.

24. S. Nawang, I. Endo, M. Iinuma, et al. Parametric Xray Study from Textured Molybdenum Polycrystal // J. Phys. Soc. Jpn.. 2006, v. 75, p. 124705.

25. Y. Takabayashi, I. Endo, K. Ueda, C. Moriyoshi, A.V. Shchagin. Observation of intense PXR from textured polycrystal // NIM. Section B. 2006, v. 243, p. 453-456.

26. K. Chouffani, M.Y. Andreyashkin, I. Endo, et al. Parametric X-radiation and diffracted transition radiation at REFER electron ring // NIM. Section B. 2001, v. 173, p. 241-252.

27. I. Endo, D. Iseki, T. Ohnishi, C. et al. On the origin of mysterious X-ray spectral peaks observed at the REFER electron ring // NIM. Section B. 2004, v. 217, p. 666-670.

28. J. Hyun, M. Satoh, M. Yoshida, et al. Compact and intense parametric $\mathrm{x}$-ray radiation source based on a linear accelerator with cryogenic accelerating and decelerating copper structures // Phys. Rev. Accel. Beams. 2018, v. 21, p. 014701.

Article received 10.06.2019

\section{ИССЛЕДОВАНИЕ ПАРАМЕТРИЧЕСКОГО РЕНТГЕНОВСКОГО ИЗЛУЧЕНИЯ В ПОЛИКРИСТАЛЛАХ}

\section{В.И. Алексеев, А.Н. Елисеев, Е.Ф. Иррибарра, И.А. Кищин, А.С. Кубанкин, Р.М. Нажмудинов}

Рассмотрено параметрическое рентгеновское излучение (ПРИ), возникающее при взаимодействии заряженных частиц с поликристаллическими мишенями. Представлен обзор современного состояния исследования ПРИ в поликристаллах: существующих теорий, перспектив применения и проведенных экспериментов с учетом развития экспериментальных возможностей.

\section{ДОСЛІДЖЕННЯ ПАРАМЕТРИЧНОГО РЕНТГЕНІВСБКОГО ВИПРОМІНЮВАННЯ В ПОЛІКРИСТАЛАХ}

\section{В.І. Алексеєв, А.Н. Слисеє,, Е.Ф. Іррібарра, І.А. Кищин, А.С. Кубанкін, Р.М. Наж.мудинов}

Розглянуто параметричне рентгенівське випромінювання (ПРВ), що виникає при взаємодії заряджених частинок $з$ полікристалічними мішенями. Представлено огляд сучасного стану дослідження ПРВ в полікристалах: існуючих теорій, перспектив застосування і проведених експериментів з урахуванням розвитку експериментальних можливостей. 